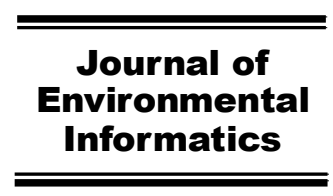

www.iseis.org/jei

\title{
Prediction of Hydraulic Conductivity of Soil Bentonite Mixture Using Hybrid-ANN Approach
}

\author{
A. K. Mishra, B. Kumar*, and J. Dutta \\ Department of Civil Engineering, Indian Institute of Technology Guwahati, Guwahati 781039, India
}

Received 26 August 2014; revised 16 December 2014; accepted 21 December 2014; published online 25 February 2015

\begin{abstract}
Due to its low hydraulic conductivity compacted soil-bentonite mixture is widely used as a barrier material at waste disposal site. The experimental determination of hydraulic conductivity of soil-bentonite mixture, which depends on the various physical and chemical and mineralogical factors, requires expensive and time consuming setup. Thus, a hybrid neural network model (combining genetic algorithm with neural network) is presented here as a complementary tool to model hydraulic conductivity of soil-bentonite mixture. The prediction capability of the model has been found to be satisfactory. The developed model yielded correlation coefficients of 0.98 and 0.97 for training and testing data sets, respectively. The proposed model was compared with conventional neural network models by using different statistical indicators such as Nash-Sutcliffe model efficiency and discrepancy ratio with standard deviation. It was found that the predictions obtained from developed model agreed well with experimental observations. Identification of important parameters and ranking their order of influence on hydraulic conductivity has been discussed by using input significance test.
\end{abstract}

Keywords: bentonite, genetic algorithm, hydraulic conductivity, liquid limit, neural network

\section{Introduction}

To minimize or eliminate the risk of the ground water being contaminated due to the toxic chemicals present in the waste leachate, the design of waste disposal facilities typically involves some form of barrier which separates the waste from the groundwater system. The barrier material should possess a low value of hydraulic conductivity. Due to its high swelling capacity and contaminant adsorption capability, bentonite is used as a barrier material. Bentonite, which is derived from the in situ chemical alteration of volcanic ash (Mitchell and Soga, 2005) is primarily composed of mineral Montmorillonite $\left(\mathrm{Al}_{1.7} \mathrm{Mg}_{0.3}\right)\left[\mathrm{Si}_{4} \mathrm{O}_{10}(\mathrm{OH})_{2}\right]^{-0.3}(\mathrm{M})^{+0.3}$, where $\mathrm{M}$ represents the exchangeable cation, exerts a significant influence on the properties of the bentonite. Fine particles, interlayer swelling and a thick layer of bound water associated with Montmorillonite cause bentonite to exhibit low permeability to passage of water (Mesri and Olson, 1971).

In order to achieve a higher compacted density and to reduce the shrinkage due to drying, bentonite is generally mixed with a locally available soil. Generally, a small amount of bentonite, typically $20 \%$ by its dry weight (Daniel, 1987 ;

\footnotetext{
* Corresponding author. Tel.: 0091-258-3612420; fax: 0091-361-2582440.

E-mail address: bimk@iitg.ernet.in (B. Kumar).
}

ISSN: 1726-2135 print/1684-8799 online

(C) 2016 ISEIS All rights reserved. doi: 10.3808/jei.201500292
Chapuis et al., 1992; Gleason et al., 1997), is used for this purpose in a soil-bentonite mixture. High swelling potential of bentonite in the presence of water resulting in the formation of a relatively "tight" soil matrix (Howell and Shackelford, 1997) and provide a lower hydraulic conductivity value to soil-bentonite mixture. Since the hydraulic conductivity is one of the most important design criteria for the material to be used as a barrier material, hydraulic conductivity test is carried out on soil-bentonite mixture before its being used at the waste disposal site. However due to very low hydraulic conductivity of sand-bentonite mixture, this test is not only time consuming but also expensive. Hence, it is very essential to develop a model to predict the hydraulic conductivity of soil-bentonite mixture.

In recent years, there has been growing interest in utilizetion of artificial intelligence based soft-computing techniques for modeling of complicated engineering problems. Soft computing is an emerging paradigm based on the backbone of artificial intelligence, evolutionary/bio-inspired computing and probabilistic computing. These allow developing of statistical black-box models based entirely on historical/experimental data. The suitability of application of soft computing comes from the fact that it allows for uncertainties in measured values. These "black-box" models are purely statistical models and model parameters are adjusted by providing training data so as to give predictions for independent and new inputs. Primarily, soft computing techniques include artificial neural network (ANN), fuzzy logic, genetic algorithms (GA), particle swarm optimization (PSO) etc. Soft computing has been 
employed extensively in geotechnical engineering with varying applications. Najjar and Basheer (1996) evaluated the permeability of compacted clay liners utilizing computational neural networks (CNN). The developed CNN models were used to predict the permeability of compacted clay for a known set of soil properties and field conditions. Shahin et al. (2002) predicted the settlement of shallow foundations on cohesionless soils using ANN. Samui and Kumar (2006) has used neural network for two layer slope stability problem. Kumar and Samui (2008) analyzed pore water pressure response through neural network. Erzin et al (2009) studied the hydraulic conductivity of compacted fine grained soils developing ANN and multiple regression analysis (MRA) models. Lim and Kolay (2009) predicted hydraulic conductivity of tropical soils by using ANN and demonstrated a comparison between the conventional estimation of hydraulic conductivity by using Shepard's equation and the predicted hydraulic conductivity from ANN. Özgan (2009) used neural network to estimate the soil particle diameter under varying quantity of Sodium Hexametaphosphate. Bektas and Özgan (2010) further used adaptive neuro fuzzy inference system for estimating particle diameter of soils. Shahin (2010) developed ANN models for predicting axial capacity of pile foundations. Das et al. (2010) utilized computational intelligence techniques; artificial neural network and support vector machine to develop models to predict swelling pressure of soil from the inputs; natural moisture content, dry density, liquid limit, plasticity index, and clay fraction of the soil. Jain et al. (2010) utilized ANN technique to predict the shear strength parameters of medium compressibility soil, which is influenced by basic properties of soil in unconsolidated undrained conditions. Das et al. (2011) utilized artificial intelligence to predict maximum dry density and unconfined compressive strength of cement stabilized soil using inputs like liquid limit, plasticity index, clay fraction, sand, gravel, moisture content and cement content. Based on different statistical criteria the support vector machine (SVM) models were found to be better than ANN models for the prediction of maximum dry density and unconfined compressive Strength of cement stabilized soil. Adarsh et.al (2012) examined the potential of two soft computing techniques, namely, SVM and genetic programming (GP), to predict ultimate bearing capacity of cohesionless soils beneath shallow foundations. Das et al. (2012) used ANN and SVM for predicting the field hydraulic conductivity of clay liners. Manouchehrian et.al (2014) studied slope stability for circular mode failure by developing a model using genetic algorithm.

Hydraulic conductivity prediction is one of the most challenging geotechnical engineering problems because interdependence on several parameters associated with uncertainty parameters. Thus the aim of the present work is to develop the hydraulic conductivity predictor by employing soft computing tool. The most versatile learning algorithm for the feed forward layered neural network is backpropagation. The backpropagation learning law is a supervised error-correction rule in which the output error, that is, the difference between the desired and the actual output is propagated back to the hidden layers. There are some drawbacks to backpropagation. For one, there is the "scaling problem". Backpropagation works well on simple training problems. However, as the problem complexity increases (due to increased dimensionality and/or greater complexity of the data), the performance of backpropagation falls off rapidly. The performance degradation appears to stem from the fact that complex spaces have nearly global minima which are sparse among the local minima. Backpropagation cannot handle discontinuous optimality criteria or discontinuous node transfer functions. This precludes its use on some common node types and simple optimality criteria. Genetic algorithm, by working with a population of solutions, can seek many local minima, and thus increase the likelihood of finding global minimum. This advantage of the genetic algorithm can be applied to neural networks to optimize the topology and weight parameters. Genetic algorithm has the potential of producing a global minimum of the weight space and thereby avoiding local minima which is the most shortcoming of the back propagation algorithm. Thus, a hybrid model (combining genetic algorithm with neural network) has been adopted in the present work to model the hydraulic conductivity of soil-bentonite mixture.

\section{Materials and Methods}

Fifteen different types of bentonite from the different sources in Japan and the U.S.A. were selected for this study. Fifteen different types of mixed were obtained by mixing each bentonite with a locally available soil in a ratio of 20:100 by their dry weight. The physical and chemical properties of the bentonites and soil are listed in Table 1.

\subsection{Testing Procedures}

The free swelling of the bentonites was determined according to ASTM 5890 (2001). Hydrometer analysis as well as dry sieving was carried out as per as ASTM D 422-63 (2002) to determine the grain size distributions of bentonite and soil. Liquid limit of the bentonites as well as soil-bentonite mixtures were carried by Casagrande's method (ASTM D 4318,2000 ) and fall cone method (JGS 0142, 2000) and the average value of these two was taken as the liquid limit. Methylene blue index test (ASTM C 837-99, 1984) was carried out to determine the percentage of Montmorillonite present in the bentonite. The cation exchange capacity (CEC) and exchangeable cations of the bentonites and the soil were determined by the ammonium acetate method as described by Chapman (1965) and Pratt (1965) respectively. The consolidation test was carried out in to determine the hydraulic conductivity on the mixtures using a standard consolidometer with $60 \mathrm{~mm}$ in diameter and $20 \mathrm{~mm}$ in thickness according to ASTM D 2435 (1996). The samples were prepared by adding de-ionized (DI) water to the different soil and bentonite mixtures, and the initial water content of the samples was adjusted to their respective liquid limit. The consolidation ring was immersed in the DI water and entire consolidation cell was enclosed within a plastic bag to reduce evaporation. Then the 
Table 1. The Physical and Chemical Properties of the Bentonites and Soil

\begin{tabular}{lllllllll}
\hline Bentonite/Soil type & LLB $(\%)$ & LLM $(\%)$ & Activity & CF $(\%)$ & CEC & MM $(\%)$ & ESP $(\%)$ & FS $(\mathrm{mL} / 2 \mathrm{~g})$ \\
\hline Western bond & 678.0 & 133 & 7.2 & 85.7 & 83.3 & 65.7 & 44.9 & 29 \\
Super clay & 615.5 & 140.5 & 6.9 & 82.8 & 72.3 & 57.1 & 64.5 & 25 \\
Volclay & 567.0 & 123.5 & 6.4 & 80.8 & 80.7 & 62.8 & 44.2 & 29 \\
Federal FB-1 & 522.6 & 121.22 & 5.9 & 78.8 & 64.7 & 49.2 & 28.1 & 24 \\
Federal FB-2 & 542.0 & 119.6 & 6.1 & 79.3 & 64.2 & 48.5 & 23.6 & 21 \\
Federal FB-3 & 560.9 & 134.03 & 6.3 & 79.0 & 62.6 & 48.5 & 30.6 & 20 \\
Premiumgel & 511.2 & 118 & 6.3 & 74.1 & 92.4 & 53.5 & 53.8 & 24 \\
Neokunibond & 510.5 & 102.3 & 6.4 & 69.5 & 77.0 & 70 & 51.8 & 19 \\
Asama & 481.0 & 83.63 & 5.8 & 73.6 & 70.1 & 40 & 23.8 & 13 \\
Kunigel VAS & 391.4 & 92.7 & 4.8 & 69.2 & 61.0 & 72.8 & 53.3 & 21 \\
Akagi & 360.1 & 73.15 & 4.9 & 62.0 & 84.2 & 45.7 & 25.1 & 14 \\
Hotaka & 310.5 & 78.5 & 4.2 & 61.4 & 85.1 & 45 & 19.6 & 14 \\
New Hotaka & 290.2 & 90.67 & 3.8 & 60.1 & 95.6 & 54.3 & 25.2 & 15 \\
Kunibond & 192.2 & 85.22 & 2.5 & 53.1 & 82.7 & 72.3 & 19.9 & 9 \\
Panther creak & 119.4 & 74.08 & 2.1 & 32.4 & 81.4 & 50 & 1.7 & 6 \\
Soil & 52.0 & - & 1.9 & 12.0 & 18.8 & - & - & 0 \\
\hline
\end{tabular}

*LLB = Liquid limit of bentonite; LLM = Liquid limit of soil-bentonite mixtures; CF = Clay fraction $(\%)$; CEC = Cation exchange capacity $\left(\mathrm{cmol}_{\mathrm{c}} / \mathrm{kg}\right) ; \mathrm{MM}=$ Montmorillonite content $(\%) ; \mathrm{ESP}=$ Exchangeable sodium percentage $(\%)$; FS=Free swelling .

consolidation cells were allowed to equilibrate for 24 hour prior to commencing the test. All the samples were initially loaded with a stress of $4.9 \mathrm{kPa}$ and increased gradually by an increment ratio of 1 as per ASTM D 2435 (1996) (i.e. increased by $4.9,9.8,19.6,39.2 \mathrm{kPa}$, etc. at each step) to a maximum pressure of $1,254.4 \mathrm{kPa}$.

\subsection{Determination of Hydraulic Conductivity}

For each pressure increment the change in the thickness of the soil sample was measured from the readings of the dial gauge. The change in the void ratio corresponding to an increase in the overburden pressure was calculated as:

$\Delta e=\Delta H\left(1+e_{0}\right) / H$

where $\Delta e=$ Change in void ratio of sample due to increase in overburden pressure, $\Delta H=$ Change in the thickness of sample due to increase in overburden pressure, $H=$ Initial thickness of the sample, and $e_{0}=$ Initial void ratio of the sample.

From the consolidation test result, a time-settlement curve was obtained at each pressure increment. The coefficient of consolidation $\left(c_{v}\right)$ was obtained using Taylor's square root time method (Taylor, 1942). The co-efficient of volume change $\left(m_{v}\right)$ was calculated as:

$m_{y}=a_{y} /\left(1+e_{0}\right)$

where $a_{v}=$ Coefficient of compressibility $=\Delta e / \Delta \sigma$ and $\Delta \sigma=$ Change in pressure.

The hydraulic conductivity $(k)$ was calculated using the Equation (3) for various pressure increments using the coefficient of consolidation and coefficient of volume change: $k=c_{y} m_{y} \gamma_{w}$

where $\gamma_{w}$ is the unit weight of the pore fluid.

\section{Modeling Approach}

In this paper, a hybrid algorithm using genetic algorithm (GA) technique is proposed to optimize parameters of the Multi-Layer Perceptron Neural Networks (MLPNN). A simple chromosome representation is used, which contains information about connections, weights and biases of the MLPNN. The parameter learning process, based on GA technique and backpropagation algorithm, is a two-step learning process. In the first step, the initial parameters, such as weights and biases of the neural network are tuned by the GA. In the second step, the backpropagation algorithm and the Levenberg-Marquadtt method is introduced to train the initial neural network to yield optimal values of weights and biases of the ANN. The block diagram of the proposed hybrid algorithm is depicted by Figure 1. This model describes a hybrid learning algorithm of MLPNN by using the GA to optimize the parameters of the network. All the parameters of the network are encoded to form a long chromosome and tuned by the GA. Then, as a result of the GA process, the backpropagation (BP) algorithm is used to train the network. The procedure of the hybrid BP learning algorithm is presented as follows.

\subsection{Chromosome Representation}

An MLPNN can be represented by a directed graph, encoded on a chromosome with each parameter (weights and biases). All these parameters are memorized by a row vector $C=\left(c_{i}\right), i=1,2, \ldots, M$, where $M$ is the number of all NN parameters. The chromosome can be written as: 


$$
C=\left[W_{1}, W_{2}\right]
$$

where $W_{1}$ denotes the connective weight of link between the input layer and the first hidden layer and $W_{2}$ is the connective weight of link between the hidden layer and output layer.

\subsection{Fitness Function}

The fitness function is dependent on problem and is used to evaluate the performance of each individual. The error signal of the output neuron $j$ at iteration $n$ (i.e., presentation of the $n^{\text {th }}$ training example) is defined by:

$e_{j}(n)=d_{j}(n)-y_{j}(n)$

where $d_{j}(n)$ is the simulated output and $y_{j}(n)$ is the actual desired output.

The instantaneous value of the error energy for neuron $j$ can also be defined as: $(1 / 2) e_{j}^{2}(n)$. Correspondingly, the value of $\xi(n)$ is obtained by summing $(1 / 2) e_{j}^{2}(n)$ over all neurons in the output layer (Haykin, 1999):

$\xi(n)=\frac{1}{2} \sum_{j=C} e_{j}^{2}(n)$

where the set $C$ includes all the neurons in the output layer of the network. For MLPNN it is the sum squared error. The fitness is defined as by summing $\xi(n)$ over all $n$ with respect to the set size $\mathrm{N}$; as shown by:

$$
F=\sum_{n=1}^{N} \xi(n)
$$

Here, the objective is to minimize $F(\cdot)$ subject to weights and biases.

\subsection{Selection}

The selection operator is to select individuals from the population for reproduction based on the relative fitness value of each individual. The extraction can be carried out in several ways. One of the most commonly used selection methods is the roulette wheel selection (Goldberg, 1989), where individuals are extracted in probability following a Monte Carlo procedure. The extraction probability $p_{r}\left(X_{i}\right)$ of each individual $X_{i}$ is proportional to its fitness $F\left(X_{i}\right)$ as a ratio to the average fitness of all the individuals. The offsprings are produced based on this selection.

\subsection{Crossover}

To apply the standard crossover operator the individuals of the population are randomly paired. Crossover takes two parents and performs an interpolation of the two parents. Each pair is then recombined, and the new individuals (offsprings) are formed by the interpolation of parents.

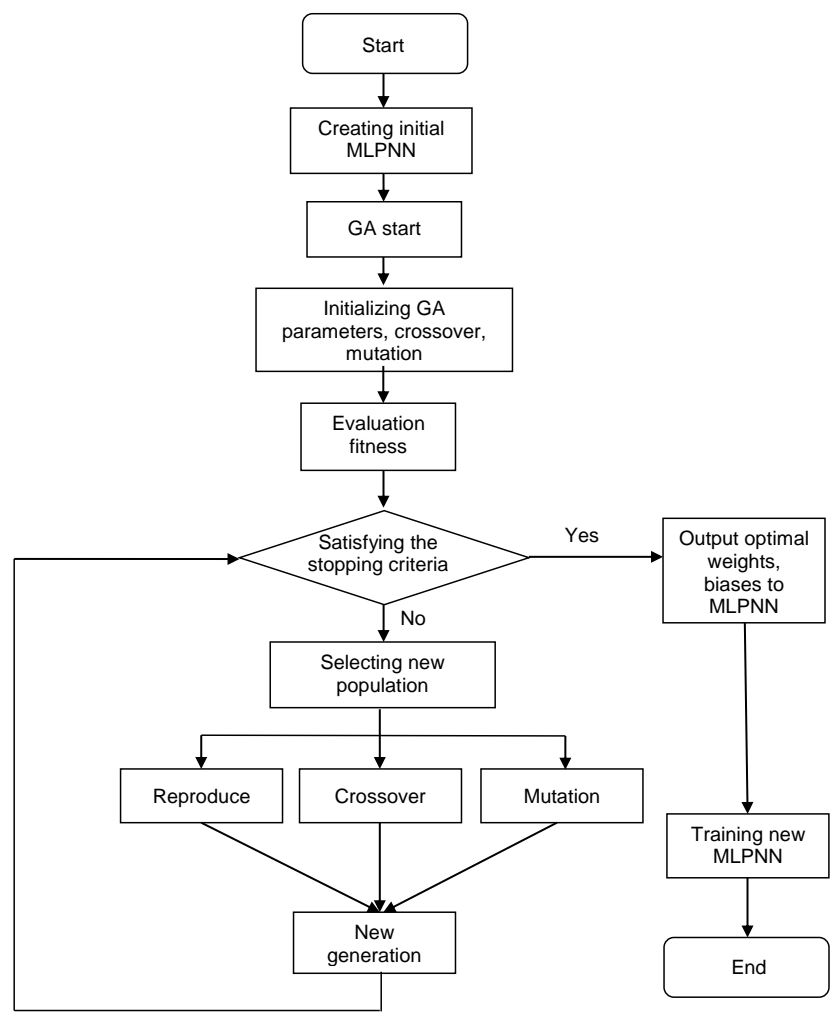

Figure 1. Flowchart of the learning algorithm.

\subsection{Mutation}

After crossover, the new individuals are subjected to mutation. Mutation prevents the algorithm being trapped in a local minimum. A variable is selected with a certain probability and its value is modified by a random value. Here, we choose non-uniform mutation method. Non-uniform mutation changes one of the genes of the parent based on a non-uniform probability distribution.

\subsection{Levenberg-Marquadt Method}

Levenberg-Marquardt works by making the assumption that the underlying function being modeled by the neural network is linear. Based on this calculation, the minimum can be determined exactly in a single step. The calculated minimum is tested, and if the error there is lower, the algorithm moves the weights to the new point. This process is repeated iteratively on each generation. The equations for changing the weights $(\Delta W)$ during training in Levenberg-Marquardt method are given as follows:

$\Delta W=\left(J^{T} J+\mu I\right)^{-1} J^{T} e$

where $J$ is the Jacobian matrix of the derivative of each error to each weight, $\mu$ is a scalar and e is an error vector. The Levenberg-Marquardt algorithm performs very well and its 
Table 2. Summary of Statistical Details of the Data

\begin{tabular}{lllll}
\hline Variables & Mean & Minimum & Maximum & Std.Dev. \\
\hline LLM & 102.24 & 74.08 & 123.50 & 19.11 \\
LLB & 415.85 & 119.40 & 567.00 & 160.01 \\
CEC & 74.38 & 61.00 & 92.40 & 10.81 \\
ESP & 31.09 & 1.74 & 53.77 & 17.01 \\
FS & 18.38 & 6.00 & 29.00 & 7.63 \\
MM & 56.14 & 40.00 & 72.80 & 11.23 \\
Activity & 4.98 & 2.07 & 6.40 & 1.63 \\
CF & 67.66 & 32.40 & 80.80 & 15.79 \\
Pressure (Kpa) & 278.49 & 4.90 & 1255.68 & 397.78 \\
Average void ratio & 1.56 & 0.74 & 2.74 & 0.53 \\
Hydraulic conductivity $(\mathrm{cm} / \mathrm{sec})$ & $5.90 \mathrm{E}-08$ & $1.71 \mathrm{E}-09$ & $6.66 \mathrm{E}-07$ & $1.08 \mathrm{E}-07$ \\
\hline
\end{tabular}

efficiency is found to be of several orders above the conventional back propagation with learning rate and momentum factor.

\section{Results and Discussion}

Entire modeling and analysis has been done by the use of neural network and genetic algorithm toolbox of MATALB ${ }^{\circledR}$ software. Since the hydraulic conductivity depends on the factors such as percentage of Montmorillonite; liquid limit of bentonite and soil-bentonite mixture; free swelling, cation exchange capacity, exchangeable sodium percentage (ESP), specific surface area and activity of bentonite along with overburden pressure and void ratio, these factors were chosen as input variables in ANN. The total number of input variables is 10 . Total number of observations used in the modeling is 73. As recommended by Masters (1993), observations are randomly divided into two statistically consistent sets: a training set for model calibration and an independent set for model testing. For development of ANN model, two-third of the total data has been used for training and one-third for testing. It should be noted that, like all empirical models, ANNs perform best in interpolation rather than extrapolation (Masters, 1993); consequently, the extreme values of the available data are included in the training set. The statistics of the data used for the training and testing sets are given in Table 2.

Once data have been divided into training and testing sets, the input and output variables are preprocessed by scaling them between 0.0 and 1.0 to eliminate their dimension and to ensure that all variables receive equal attention during training. The simple linear mapping of the variables' practical extremes to the neural network's practical extremes is adopted for scaling, as it is the most common method for this purpose (Masters, 1993). As part of this method, for each variable $x$ with minimum and maximum values $x_{\min }$ and $x_{\max }$, respecttively, the scaled value of $x_{\mathrm{n}}$ is calculated as follows: $x_{n}=\left(x-x_{\min }\right) /\left(x_{\max }-x_{\min }\right)$. The final architecture of neural net used in the analysis is 10-10-1 and given in the Figure 2.

The transfer function used in the model is tan-sigmoid for both input to hidden and hidden to output layers. The idea behind choosing sigmoid functions as transfer functions is

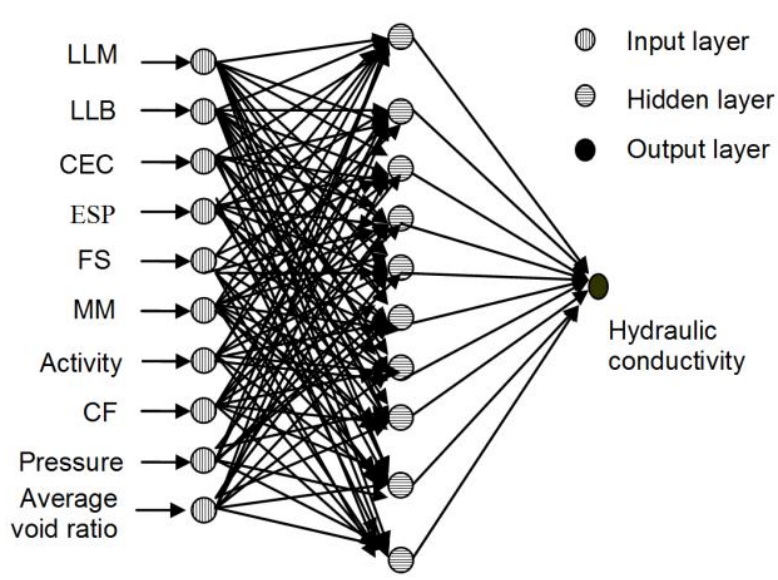

Figure 2. Single layer neural network architecture for hydraulic conductivity.

that it bears a greater resemblance to the biological neurons. In case of sigmoid functions, the output of the neurons varies continuously but not linearly with the input. Results of neural modeling are shown in Figure 3. It can be clearly seen from Figure 3 that the linear coefficient of correlation is very high between observed data and values predicted through neural nets and it is 0.98 and 0.97 in training and testing respectively.

This shows the learning and generalization performance of the network is good. Comparison has been done on the basis of Nash-Sutcliffe model efficiency and discrepancy ratio with standard deviation. The Nash-Sutcliffe model efficiency coefficient $(E)$ is used to assess the predictive power of models (Nash and Sutcliffe, 1970). It is defined as:

$E=1-\frac{\sum(\text { observed }- \text { simulated })^{2}}{\sum(\text { observed }- \text { observed mean })^{2}}$

The value of $E$ can range from $-\infty$ to 1.0 , with higher values indicating a better overall fit and 1.0 indicating a perfect fit. An efficiency of $0(E=0)$ indicates that the model predictions are as accurate as the mean of the observed data, whereas an efficiency less than zero $(E<0)$ occurs when the 
observed mean is a better predictor than the model. The discrepancy ratio and standard deviation have been used to indicate the accuracy of the goodness-of-fit. The discrepancy ratio indicates the goodness-of-fit between the predicted and observed results. One of the ways to measure the goodnessof-fit is the use of standard deviation (Yang and Simôes, 2005) based on the average value of the logarithm ratio between computed and measured results using the following equation:

$\sigma_{a}=\frac{\sqrt{\sum\left(\log \left(\frac{\text { simulated }}{\text { observed }}\right)-\bar{D}_{a}\right)^{2}}}{\text { No. of observations }-1}$

where,

$$
\bar{D}_{a}=\frac{\sum \log \left(\frac{\text { simulated }}{\text { observed }}\right)}{\text { No.of observations }}
$$

is a perfect fit for $\sigma_{a}=0$.

Two standard training algorithms, the Levenberg-Marquardt (LM) optimization and the BFGS (Broyden, Fletcher, Goldfarb, and Shanno) quasi-Newton method, have been used to compare the GA-ANN results. Table 3 enlists the results. Table 3 suggests that present developed model performs better than other methods when compared with different statistical measures.

The form of the developed model is as follows:
$Y=f_{2}\left(W_{2} f_{1}\left(W_{1} X\right)\right)$

where $Y[1]$ is the output value of the model, $W_{1}\left[\begin{array}{lll}10 & 10]\end{array}\right.$ is the input-hidden layer weight values and $W_{2}\left[\begin{array}{ll}1 & 10\end{array}\right]$ hidden-output layer weight values. $X\left[\begin{array}{ll}10 & 1\end{array}\right]$ is the input patterns and $f_{1}$ and $f_{2}$ are the hyperbolic tangent transfer functions. The developed model has been applied to the independent data sets taken from Mishra et al. (2008) for prediction of hydraulic conductivity. Figure 4 shows the parity plot of hydraulic conductivity. It can be seen from the Figure 4 that linear coefficient of correction is 0.97 and the value of $E$ and $\sigma_{a}$ are 0.92 and 0.024 . Thus it can be said that the applicability of the present model is satisfactory and resulting weights can be used for further field applications.

A variety of methods are available for the estimation of the contribution of predictor variables in relationship to the output. For example, Partial Derivative method provides a profile of the output variations for small changes of each input variable and classification of the relative contributions of each variable to the network output. 'Stepwise' method is based on the classical stepwise approach that consists of adding or rejecting step by step one input variable and noting the effect on the output results (Gevrey et al., 2003). 'Profile' method proposed by Lek et al. (1996) studies each input variable successively when the others are blocked at fixed values. In the neural network, the connection weights between neurons are the linkages between the input and the output of the network, and therefore are the link between the problem and the solution (Olden and Jackson, 2002). Garson algorithm or

Table 3. Comparative Analysis of Different Intelligent Predictors

\begin{tabular}{lllllll}
\hline \multirow{2}{*}{ Methodology } & $\mathrm{R}^{2}$ & \multicolumn{3}{c}{$\mathrm{E}$} & $\sigma_{\alpha}$ & \\
\cline { 2 - 7 } & Training & Testing & Training & Testing & Training & Testing \\
\hline GA-ANN & 0.98 & 0.97 & 0.97 & 0.94 & 0.02 & 0.07 \\
ANN-LM & 0.97 & 0.92 & 0.95 & 0.92 & 0.092 & 0.28 \\
ANN-BFGS & 0.94 & 0.88 & 0.92 & 0.9 & 0.06 & 0.13 \\
\hline
\end{tabular}
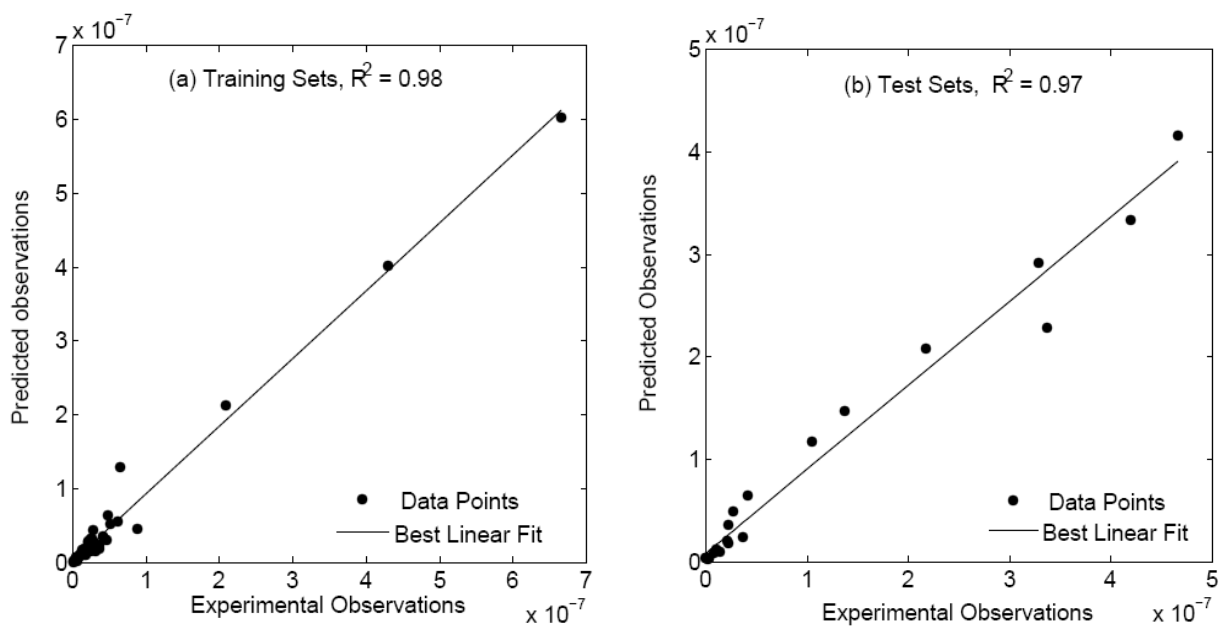

Figure 3. Performance of hybrid neural network model for training and test sets. 
'Weights' method includes partitioning the connection weights to determine the relative importance of the various inputs. In the present work, Garson algorithm has been implemented to know the importance of the input variables on output. Garson (1991) proposed a method for partitioning the neural network connection weights in order to determine the relative importance of each input variable in the network. The methodology for this algorithm is as follows:

(a) For each hidden neuron $\mathrm{h}$, divide the absolute value of the input-hidden layer connection weight by the sum of the absolute value of the input-hidden layer connection weight of all input neurons, i.e., for $h=1$ to $n h$, and $i=1$ to $n i$ :

$$
A_{i h}=\frac{\left|W_{i h}\right|}{\sum_{i=1}^{n i}\left|W_{i h}\right|}
$$

(b) For each input neuron $i$, divide the sum of the $A_{i h}$ for each hidden neuron by the sum for each hidden neuron of the sum for each input neuron of $A_{i h}$, multiply by 100 . The relative importance of all output weights attributable to the given input variable is then obtained. For $i=1$ to $n i$ :

$$
R I(\%)_{i}=\frac{\sum_{n=1}^{n h} A_{i h}}{\sum_{n=1}^{n h} \sum_{i=1}^{n i} A_{i h}} \times 100
$$

Garson's algorithm is based on the weight matrices of the neural network. The calculations have been shown in the Table 4.

As it can be seen from Table 4, the percentage of Montmorillonite has much more effect on hydraulic conductivity of soil-bentonite mixture than others. Since Montmorillonite directly influences the thickness of the diffuse double layer

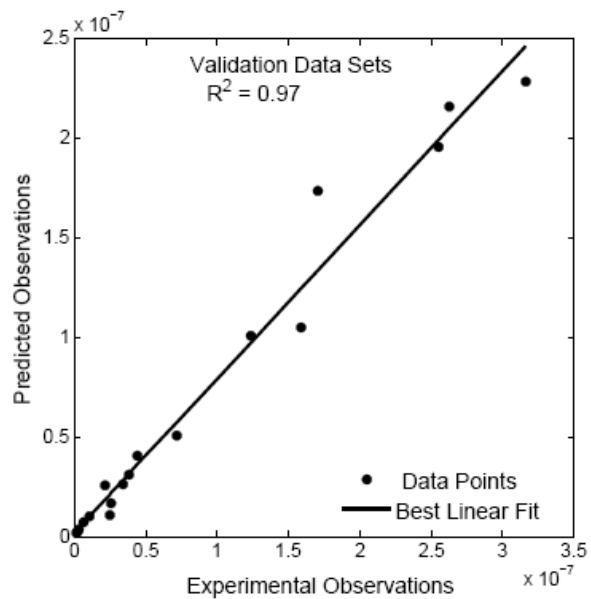

Figure 4. Prediction of hydraulic conductivity using present model (observation taken from Mishra et al., 2008). which in turn controls the hydraulic conductivity, it predicts the hydraulic conductivity quite accurately in comparison to other parameters. The other important parameter is the liquid limit of the bentonite as it is also related with the amount of diffuse double layer water present. On the other hand, percentage of clay fraction present in the soil has least influenced on the hydraulic conductivity amongst all the parameters followed by liquid limit of mixture and cation exchange capacity. Since only those clay particle which exhibits swelling behaviour influences the hydraulic conductivity, percenttage of clay fraction, which do not distinguishes swelling and non-swelling clay particles type, it occupies the least position.

Table 4. Input Significance and Ranking of the Variables

\begin{tabular}{lll}
\hline Variables & \% Significance & Rank \\
\hline LLM & 3.98 & 9 \\
LLB & 21.35 & 2 \\
CEC & 4.56 & 8 \\
ESP & 6.85 & 5 \\
FS & 8.61 & 4 \\
MM & 24.56 & 1 \\
Activity & 6.37 & 6 \\
CF & 3.95 & 10 \\
Pressure (Kpa) & 5.68 & 7 \\
Average void ratio & 14.04 & 3 \\
\hline
\end{tabular}

\section{Conclusions}

In this study an attempt has been made to predict the hydraulic conductivity of soil-bentonite mixture using the hybrid-neural network model. In this way, a qualitative effect of all types of parameters can be incorporated in the predicttion analysis. The generalization capacity of the model is very good considering there are so many different parameters affectting hydraulic conductivity. Based on different statistical performance criteria, the developed model is found to be more efficient compared with the conventional ANN model. The input significance test shows that the percentage of Montmorillonite and liquid limit of the bentonite are the most important parameters affecting hydraulic conductivity of soil-bentonite mixture.

\section{References}

Adarsh, S., Dhanya, R., Krishna, G., Merlin, R., and Tina, J. (2012). Prediction of ultimate bearing capacity of cohesionless soils using soft computing techniques. ISRN Artificial Intell., 2012, 1. http://dx.doi.org/10.5402/2012/628496.

ASTM (1984). Standard Test Method for Methylene Blue Index of Clay, C 837-99, American Society for Testing and Materials, Philadelphia.

ASTM (1996). Standard Test Method for One-Dimensional Consolidation Properties of Soils, D 2435, American Society for Testing and Materials, Philadelphia.

ASTM (2000). Standard Test Methods for Liquid Limit, Plastic Limit, and Plasticity Index of Soils, D 4318, American Society for Testing and Materials, Philadelphia. 
ASTM (2001). Standard Test Method for Swell Index of Clay Mineral Component of Geosynthetic Clay Liners, D 5890, American Society for Testing and Materials, Philadelphia.

ASTM (2002). Standard Test Method for Particle-Size Analysis of Soils, D 422-63, American Society for Testing and Materials, Philadelphia.

Bektas, S., and Özgan, E. (2010). Adaptive neuro fuzzy inference system for estimating particle diameter of soils in micro structure for varying quantities of sodium hexametaphosphate. Sci. Res. Essays, 5, 782-789.

Özgan, E. (2009). Neural network based modelling of soil particle diameters under varying quantity of sodium hexametaphosphate. Asian J. Chem., 21, 2632-2642.

Chapman, H.D. (1965). Cation exchange capacity, in C.A. Black et al. (Eds.), Methods of Soil Analysis: Part 2 - Chemical and Microbiological Properties, 2nd edition, Soil Science Society of America, Madison, Wisconsin, USA, pp. 891-895.

Chapuis, R.P., Lavoei, J., and Girad, D. (1992). Design, construction, performance, and repair of the soil-bentonite liners of two lagoons. Can. Geotech. J., 29(4), 638-649. http://dx.doi.org/10.1139/t92-07 1.

Daniel, D.E. (1987). Earthen liners for land disposal facilities, in R.D. Woods (Ed.), Geotechnical Practice for Waste Disposal, Geotechnical Special Publication, No. 13, ASCE, New York, pp. 21-39.

Das, S.K., Samui, P., Sabat, A.K., and Sitharam, T.G. (2010). Prediction of swelling pressure of soil using artificial intelligence techniques. Environ. Earth Sci., 61, 393-403. http://dx.doi.org/10.1 007/s12665-009-0352-6.

Das, S.K., Samui, P., and Sabat, A.K. (2011). Application of artificial intelligence to maximum dry density and unconfined compressive strength of cement stabilized soil. Geotech. Geol. Eng., 29, 329-342. http://dx.doi.org/10.1007/s10706-010-9379-4.

Das, S.K., Samui, P., and Sabat, A.K. (2012). Prediction of field hydraulic conductivity of clay liners using an artificial neural network and support vector machine. Int. J. Geomech., 12, 606-61 1. http://dx.doi.org/10.1061/(ASCE)GM.1943-5622.0000129.

Erzin, Y., Gumaste, S.D., Gupta, A.K., and Singh, D.N. (2009). Artificial neural network (ANN) models for determining hydraulic conductivity of compacted fine grained soils. Can. Geotech. J., 46, 955-968. http://dx.doi.org/10.1139/T09-035.

Garson, G.D. (1991). Interpreting neural-network connection weights. Artificial Intell. Expert, 6, 47-51.

Gevrey, M., Dimopoulos, I., and Lek, S. (2003). Review and comparison of methods to study the contribution of variables in artificial neural network models. Ecol. Model., 160, 249-264. http://dx.doi.org/10.1016/S0304-3800(02)00257-0.

Gleason, M., Daniel, D.E., and Eykholt, G.R. (1997). Calcium and sodium bentonite for hydraulic containment applications. $J$. Geotech. Geoenviron. Eng., 123(5), 438-445. http://dx.doi.org/10.1 061/(ASCE)1090-0241(1997)123:5(438).

Goldberg, D.E. (1989). Genetic Algorithms in Search, Optimization and Machine Learning, Addison-Wesley, Reading, MA.

Haykin, S. (1999). Neural networks: A Comprehensive Foundation, Prentice-Hall, Upper Saddle River, NJ.

Howell, J.L., and Shackelford, C.D. (1997). Hydraulic conductivity of sand admixed processed clay mixtures, in Proc. of $14^{\text {th }}$ International Conference on Soil Mechanics and Foundation Engineering, Hamburg, vol. 1, Balkema, Rotterdam, pp. 307-310.

Jain, R., Jain, P.K., and Bhadauria, S.S. (2010). Computational approach to predict soil shear strength. Int. J. Eng. Sci. Technol.,
2(8): 3874-3885

JGS (2000). Test Method for Liquid Limit and Plastic Limit of Soils, JGS-0142, Japanese Geotechnical Society.

Kumar, B., and Samui, P. (2008). Application of ANN for predicting pore water pressure response in a shake table test. Int. J. Geotech. Eng., 2, 153-160. http://dx.doi.org/10.3328/IJGE.2008.02.02.153-1 60.

Lek, S., Delacoste, M., Baran, P., Dimopoulos, I., Lauga, J., and Aulagnier, S. (1996). Application of neural networks to modeling nonlinear relationships in ecology. Ecol. Model., 90, 39-52. http://dx.doi.org/10.1016/0304-3800(95)00142-5.

Lim, D.K.H., and Kolay, P.K. (2009). Predicting hydraulic conductivity $(\mathrm{k})$ of tropical soils by using artificial neural network (ANN), J. Civ. Eng., 1, 1-6.

Manouchehrian, A., Gholamnejad, J., and Sharifzadeh, M. (2014). Development of a model for analysis of slope stability for circular mode failure using genetic algorithm. Environ. Earth Sci., 71, 1267-1277. http://dx.doi.org/10.1007/s12665-013-2531-8.

Masters, T. (1993). Practical Neural Network Recipes in C++, Academic Press, San Diego, CA.

Mesri, G., and Olsen, R.E. (1971). Mechanisms controlling the permeability of clays. Clays Clay Miner., 19, 151-158. http://dx.doi.org/10.1346/CCMN.1971.0190303.

Mishra, A.K., Ohtsubo, M., Li, L., Higashi, T., and Park, J. (2008). Effect of salt of various concentrations on liquid limit, and hydraulic conductivity of different soil bentonite mixtures. Environ. Geol., 57 (5), 1145-1153. http://dx.doi.org/10.1007/s00254-008-14 11-0.

Mitchell, J.K., and Soga, K. (2005). Fundamentals of Soil Behavior, 3rd edition, John Wiley \& Sons, Inc., New York.

Najjar, Y.M., and Basheer, I.A. (1996). Utilizing computational neural networks for evaluating the permeability of compacted clay liners. Geotech. Geol. Eng., 14, 193-212.

Nash, J.E., and Sutcliffe, J.V. (1970). River flow forecasting through conceptual models part 1 - A discussion of principles. J. Hydrol., 10, 282-290. http://dx.doi.org/10.1016/0022-1694(70)90255-6.

Olden, J.D., and Jackson, D.A. (2002). Illuminating the "blackbox": Understanding variable contributions in artificial neural networks. Ecol. Model., 154, 135-150. http://dx.doi.org/10.1016/S0304-3800 (02)00064-9.

Pratt, P.F. (1965). Sodium, in C.A. Black et al. (Eds.), Methods of Soil Analysis, Part 2 - Chemical and Microbiological Properties, 2nd edition, Soil Science Society of America, Madison, Wisconsin, USA, pp. 1031-1034.

Samui, P., and Kumar, B. (2006). Artificial neural network prediction of stability numbers for two-layered slopes with associated flow rules. Electron. J. Geotech. Eng., 11, Bundle B.

Shahin, M.A. (2010). Intelligent computing for modelling axial capacity of pile foundations. Can. Geotech. J., 47, 230-243. http://dx.doi.org/10.1139/T09-094.

Shahin, M.A., Maier, H.R., and Jaksa, M.B. (2002). Predicting settlement of Shallow Foundations using Neural Networks. J. Geotech. Geoenviron. Eng., 128, 785-793. http://dx.doi.org/10.106 1/(ASCE)1090-0241(2002)128:9(785).

Taylor, D.W. (1942). Research on Consolidation of Clays, Serial number 82, Department of Civil Engineering, Massachusetts Institute of Technology, Cambridge, Mass.

Yang, C.T., and Simôes, F.J.M. (2005). Wash load and bed-material load transport in the Yellow River. J. Hydraul. Eng. ASCE, 131, 413-418. http://dx.doi.org/10.1061/(ASCE)0733-9429(2005)131:5 (413). 